\title{
Avoiding Skin Grafts: The Local Perforator Flap in Cutaneous Defects Covering.
}

\author{
Sliesarenko S., Badiul P., Nor N., Sliesarenko D., Rudenko O., Lychkata K., Nosulko O. \\ Burns \& Plastic Surgery Centre. Dnipro. Ukraine.
}
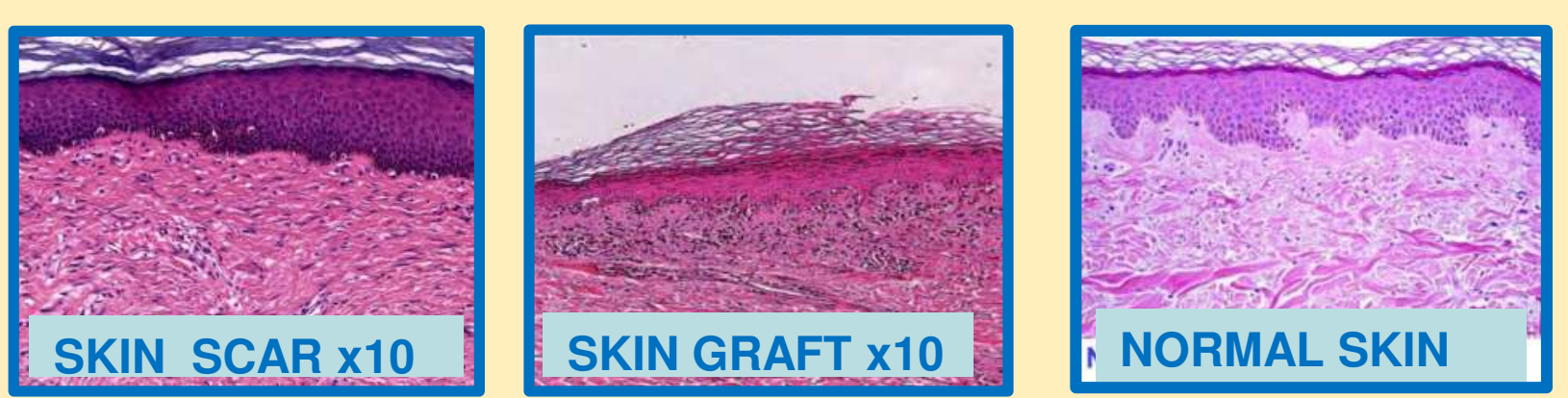

\section{Background}

Since its creation the first dermatome of 1939 skin grafts have become the most common method of wound closure. This method has long been called the "gold standard" of skin plastic. But, after surgery by attached split-thickness skin graft, does not fully recreate the lost skin. And the increased requirements of patients for the quality of life parameters require the improvement of plastic surgery in this aspect.

\section{Objectives}

To improve the efficiency of wound closure surgery, we can select cases where it is possible to avoid skin graft transplantation. Instead, close the wounds by the local perforator flaps, which will restore the skin to the most similar to the lost.
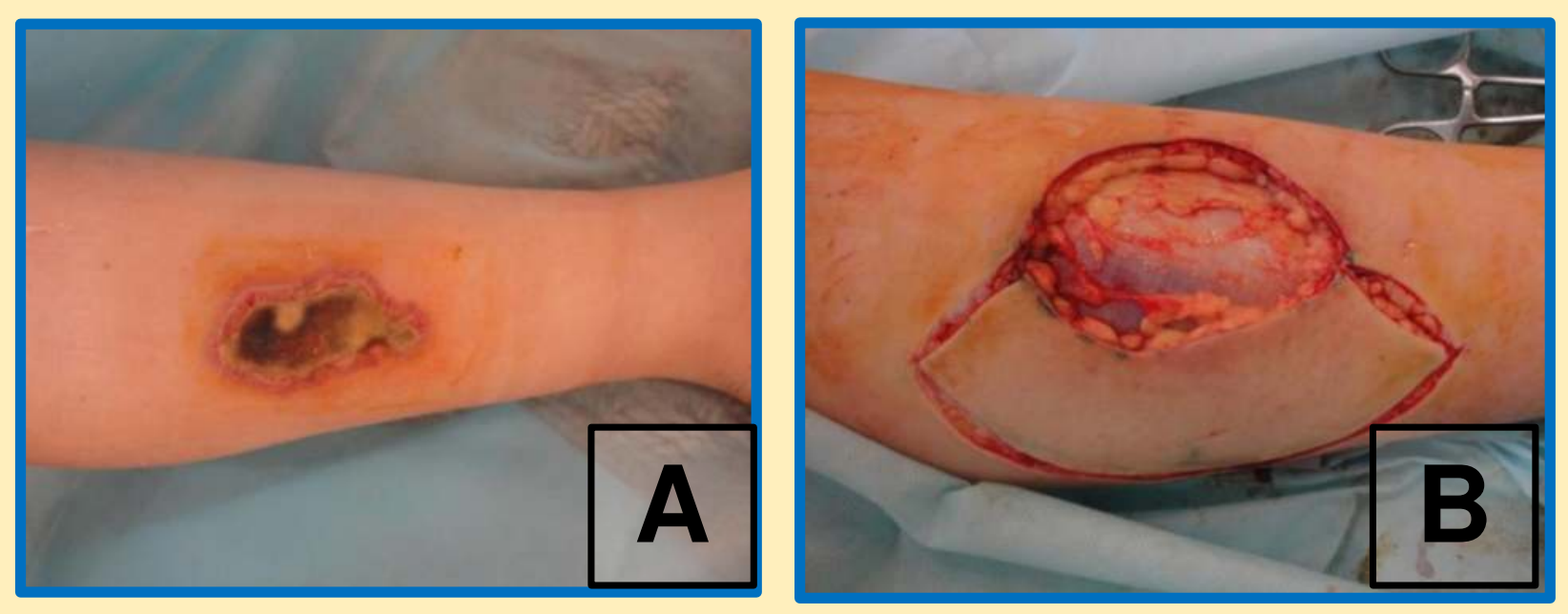

\section{Methods}

In the first group (25 patients), the $\mathrm{V}-\mathrm{Y}$ local flaps method was used. In the second group (28 patients) the Keystone local perforator flaps were used. In the third group (30 patients) skin grafts cover was used. Evaluated the rate of wound healing, the properties of the restored skin and the patient's quality of life.
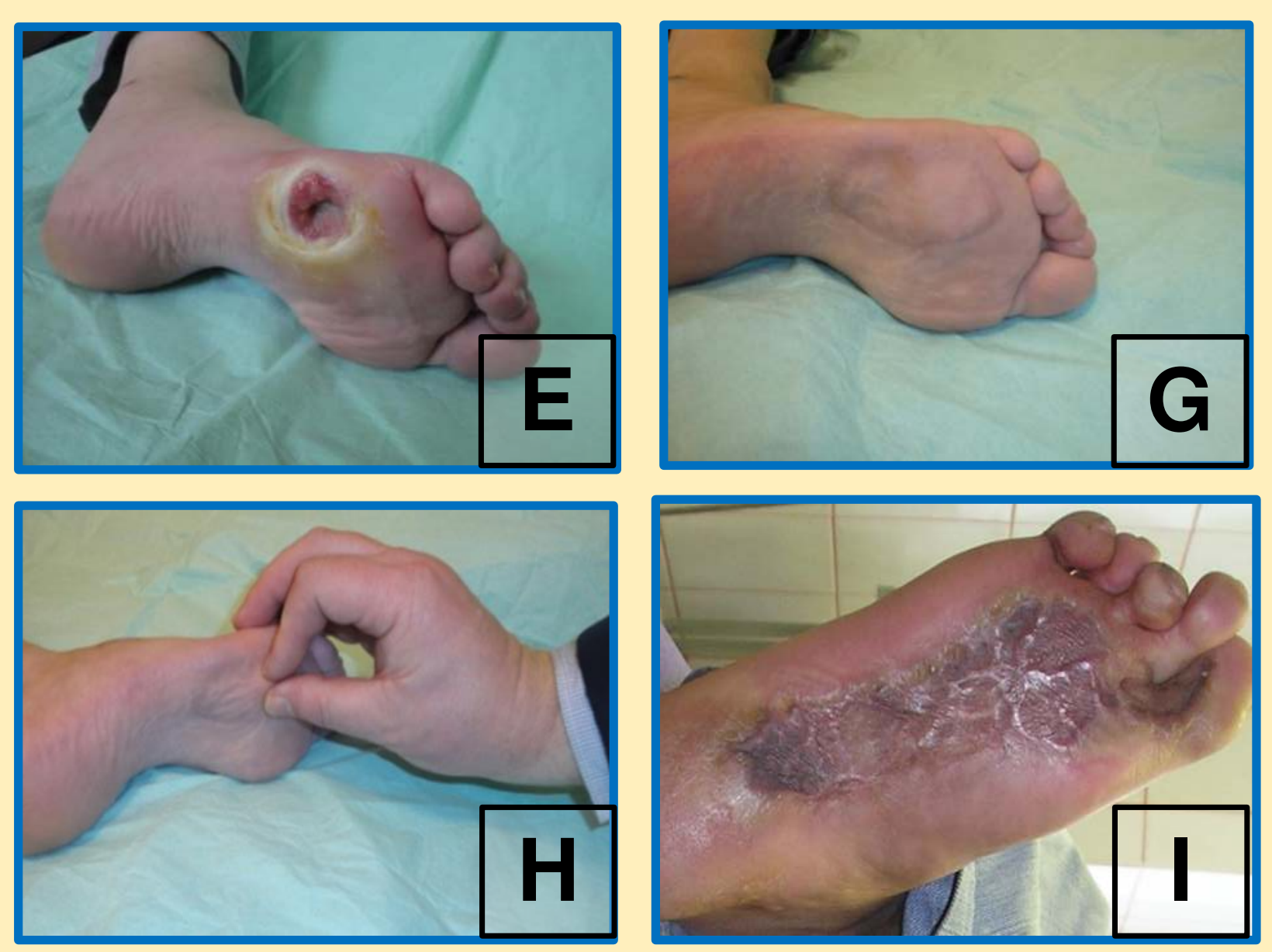

$3^{\text {rd }}$ Degree deep burn of shin $[A]$, early block excision [B], wound closed with keystone perforator flap simultaneously [C] and result [D]. Trophic wound of the foot [E], closed with keystone flap simultaneously [G] and result $[\mathrm{H}]$. Photos show that the skin restored as a result of flaps reposition [J] $[\mathrm{H}]$ has significantly better quality. than skin restored after split graft covering $[\mathrm{I}][\mathrm{K}]$.
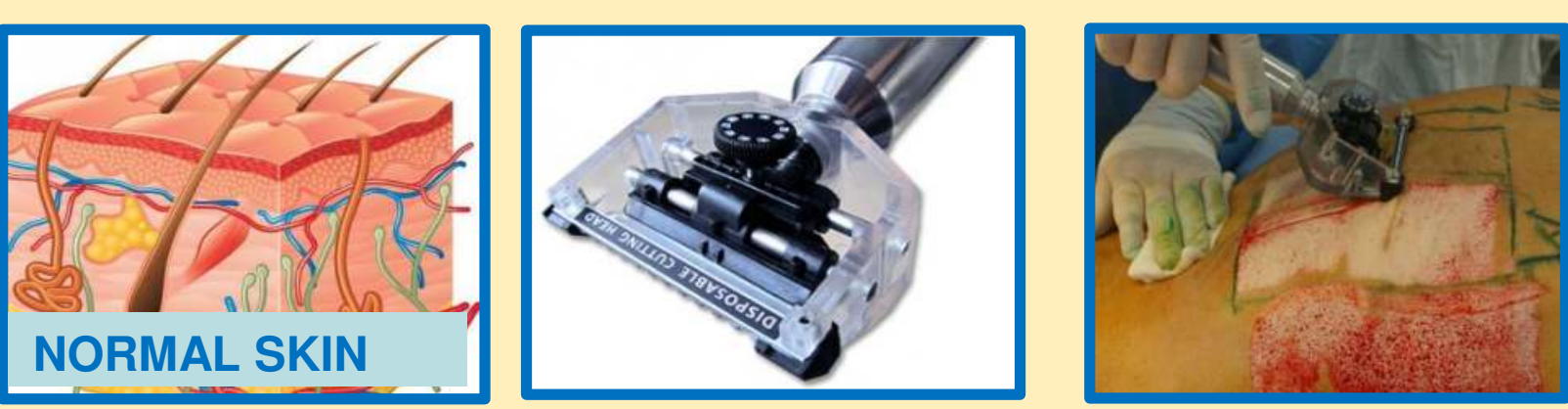

\section{Results}

All patients received complete wound healing. In the first and second groups the wounds healed 2 times faster to compare with third group and the quality of the new skin was significantly better.

\section{Conclusion}

The local perforator flaps is a versatile and reliable reconstructive option for cover small or middle size wounds. This method provides restoration of the skin similar to the lost one, considerably superior in quality to the skin restored by engraftment of skin grafts. But limitations for local flaps is such as donor-site scarring or other skin problems. We are agree in that "there is no one single flap or modification for all situations."
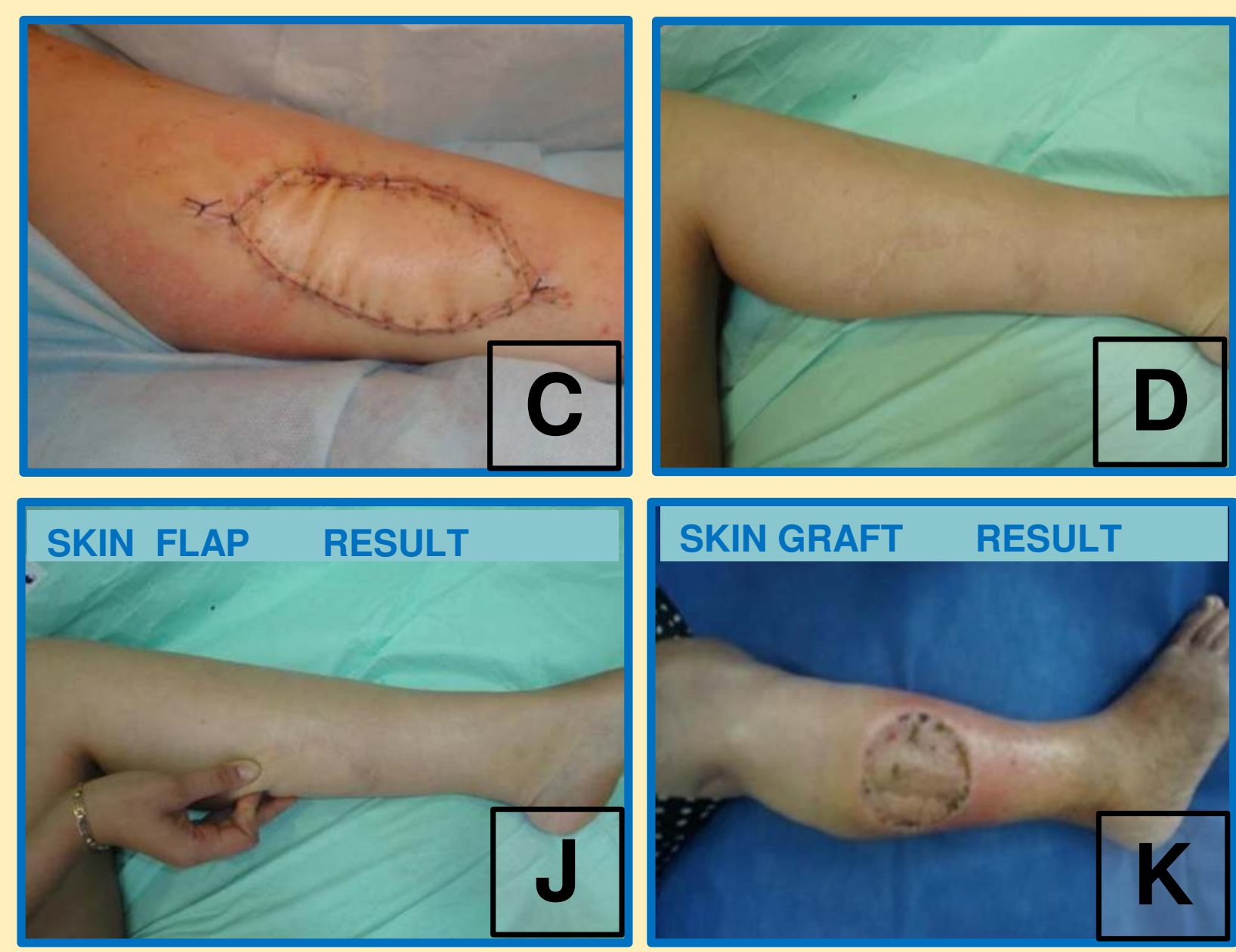

Sufficient experience the plastic surgeon help to choice the modifications of surgery and can guide to the appropriate reconstruction. Traditionally, split-thickness skin grafts were still as main method for large and extensive soft tissue reconstructions, like on circular limb wounds.

\section{References}

1. Badiul P., Sliesarenko S., Sliesarenko K. The local perforator flaps for plastic closure of extensive military wounds // Chirurgia Plastyczna i Oparzenia. - 2015. - Vol.2, Number 3. - P.59-60.

2. Hooman S., Ryan M., Scott T. Current Concepts in Lower Extremity Reconstruction // Plastic and Reconstructive Surgery. - December. - 2015.-Vol. 136, Number 6.P.815e-829e.

3. Lee L., Jamie P., Fu-Chan W. Reconstructive Surgery of the Lower Exremity (TwoVolume Set). - QMP inq. St Louis, Missouri, 2013.- 1368 p.

4. Zenn M.R., Jones G. Reconstructive Surgery. Anatomy, technique, and clinical application. - QMP, St. Louis, Missouri., 2012. - 911p. 5. Behan F.C. The keystone design perforator island flap in reconstructive surgery // ANZ J Surg. - 2003. - Vol. 73. - P. $112-120$.

6. Panchot J., Chambert J., Remashe D. et al. Geometrical analysis of V-Y advancement flap applied to the keystone flap // J Plast Reconstr Aesthet Surg. 2012. - Vol. 65(8). - P.1087-1095.

7. Buchanan P. J. Evidence-Based Medicine: Wound Closure / P.J. Buchanan, T.A. Kung, P.S. Cederna // Plastic and Reconstructive Surgery. - 2014. - Vol.134. - P. 1391-1404.

8. Stekelenburg, Carlijn M.; Jaspers, Mariëlle E. H.; Jongen, Sandra J. M. at all.Perforator-Based Interposition Flaps Perform Better Than Full-Thickness Grafts for the Release of Burn Scar Contractures: A Multicenter Randomized Controlled Trial//Plastic and Reconstructive Surgery. 139(2):501e-509e, February 2017. 